\title{
VISUAL BOARDS: MOOD BOARD, STYLE BOARD OR CONCEPT BOARD?
}

\author{
Julie Elert MUNK, Jesper Sønderskov SøRENSEN and Linda Nhu LAURSEN \\ Aalborg University, Denmark
}

\begin{abstract}
In this paper, we research the usage of visual boards. Visual boards are an important part of navigating a design process. The two most known visual boards are mood boards and style boards, which are well described in literature [3]. However specific for industrial design practice are concept boards. While these boards are commonly used in practice, where they serve as central tools for developing and communicating concept ideas, they have received proportionally less attention in literature. Even though the theory recognises the existence of concept boards, knowledge of the content, development and use of these is still limited.

Through case studies at two industrial design consultancies, we scrutinize 33 different visual boards made by design students and analyse the feedback they get from professional senior designers. In the analysis, we find concept boards are the most frequent and most central type of boards used, yet knowledge of them compared to style and mood board is scarce [2]. By scrutinizing the process of creating and receiving feedback on concepts boards in industrial design, we find three key elements and considerations for creating a productive concept board. For practice, we provide key considerations important for creating useful concept boards. We believe these may be valuable for both students and instructors of industrial design, that needs to understand or teach how to develop concept boards.
\end{abstract}

\section{Keywords: Visual boards, mood board, style board, concept boards}

\section{INTRODUCTION}

Progress in the design process is often driven by and communicated using visual tool [1]. A central tool in the visual development and communication are visual boards, whereof the most known are mood boards and style boards. Several studies have contributed with knowledge of the nature of mood boards and style boards, in terms of content and use in the process [2], [3], [4]. Visual objects have an active role in organising the process, to make it possible to balance coordination as well as creative freedom [5]. However particular for industrial design practice are the use and centrality of concept boards. While these boards are briefly mentioned in other studies theory provides little knowledge of the elements, content and utilisation of these boards. Concept boards may be defined as a type of visual board, which explores, communicates or examines a concept or parts of a concept.

Even though the theory recognises the existence of concept boards, knowledge of the content, development and use of these is still limited. In many cases these concept boards are developed by the more junior designers at a design agency, where after the concept boards then receive feedback from the senior designer and this feedback influence the further process. Navigating and communicating visual boards in a creative design process is a challenging and abstract task that many novice designers and design students struggle with every day. Every time a board is created, is presented and gets feedback, it is changing the project, which means it is either pushing it forwards or taking it a step backwards. Thus, finding and providing explicit insights on what constitutes a useful and productive concept board is valuable for enhancing the use of concept boards in the design process. These concept boards are commonly used in practice, where they serve as central tools for developing and communicating concept ideas, however they have received proportionally less attention in literature.

The study is divided into three steps: First, the theory on visual boards within the field of design has been reviewed to establish the theoretical foundation of the paper. The theory has been gathered in a model that visualizes their connection in a design process. Secondly, we analyse the use of visual boards in two industrial design studios. This will help design students to understand how to create and use the appropriate and suitable visual boards. Our contribution to the existing theory is a line of recommendations for design students and instructors to be aware in the type of visual boards deployed 
in furthering the process. The research explains an array of considerations that are important to make regarding the board's layout as much as the imagery used.

\section{VISUAL BOARDS}

As there is already researched on definitions of visual boards in the overall process, we build on this as we position our research in the following section. First, we position the use of visual boards in the overall structure of the design process (see figure 1). Then we dive into the role and character of the different types of visual boards, namely mood boards, style boards and concept boards. In this section, we outline an overall step-by-step flow of the process (see figure 2).

\subsection{Brief}

The first step in any design process is the brief. This entails a description of the given case and the restrictions of the project. The specification of the brief can vary and might be more specific in cases where a product is redesigned in contrary to cases where the company is entering a new market.

\subsection{Visual Boards}

Within the field of design, the visual boards function as a justification method to explain the design choices through visual [6]. There are 4 board types within a visual board [2]. This paper has its focus on Industrial Design (that mainly deals with product development) and divide the boards into three categories. The overall term of the three new categories is visual boards.

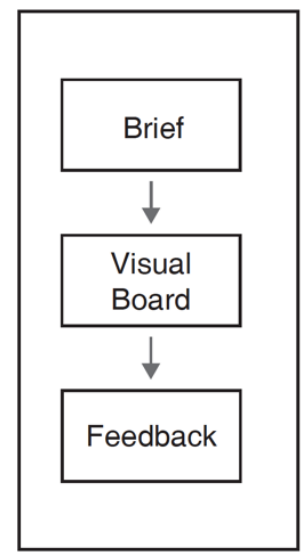

Figure 1. Overall process

\subsubsection{Mood board}

The mood board is often the first board to be created. It focuses on setting the mood and creating a story that appeals to the viewers' feelings. The purpose of the mood board is to overcome linguistic restrictions when trying to communicate the setting from a brief by using imagery to establish joint visual connotations. Often a more successful outcome can be delivered if the images used in the mood boards aim to be more abstract rather than figurative. The highly figurative images can be a hindrance or a blockade for generating new and innovative concepts [3]. This category is non-product specific, but with the product in mind, which means having a more abstract approach. The goal of this board is to communicate the setting, which the product fit in [2].

Mood boards serves its purpose in the earliest stages of the design process but can be used to get out of blockades and dead ends [3]. In general, it is important to avoid figurative imagery, in mood boards, but especially images created by large scale manufacturers and retailers (such as Nike or other big companies) causes a hindrance towards innovation and creativity, as you might tend to do the same things within your own concepts [3]. If the mood board is approved by the instructor/senior designer, next step can be initiated. If it is not approved, then the process starts over.

\subsubsection{Style board}

This visual board is a further development of the mood board and seeks to generate figurative images that fits into the abstract mood board setting. This is done through a set of visual parameters; colour, texture, shape, material, shadow grooves, etc. features from the style boards images can be directly translated to the concepts. In addition, the products used in the style board aim to be as close to what the user or client would surround themselves with [6]. The purpose of the style board is to translate the abstract setting of the mood board into specific existing products. The existing solutions are used to help tame the abstract. If the board is approved by the instructor/senior designer, next step can be initiated. If it is not approved, then a step back to the mood board is necessary and in some cases a step back to the initial brief is inevitable. 


\subsubsection{Concept board}

The concept board is often used in later stages than the mood board and style board, as these are the ones setting the framework for the project. This board has its focus on the visual communication and presentation of the developed concepts. There is no strict answer of how the presentation should be structured, but since it is often presented to a client it is preferred that it reflects, enhances or somehow emphasizes the brand, identity or image [2]. The purpose of the concept board is to develop and communicate the concept through visual means. If the board is approved by the instructor/senior designer, the next step is mostly to present the concept for the client if it is still being developed. At a later stage, the next step is to prepare the product for launch. Is the concept board not approved, one option would be to re-design the product and therefore create a new concept board? Another option is to step back into either style board or mood board to redesign these. A third option is a step all the way back to the initial brief and therefore reset the process. Developing a concept is an iterative design process, requiring focus and perseverance.

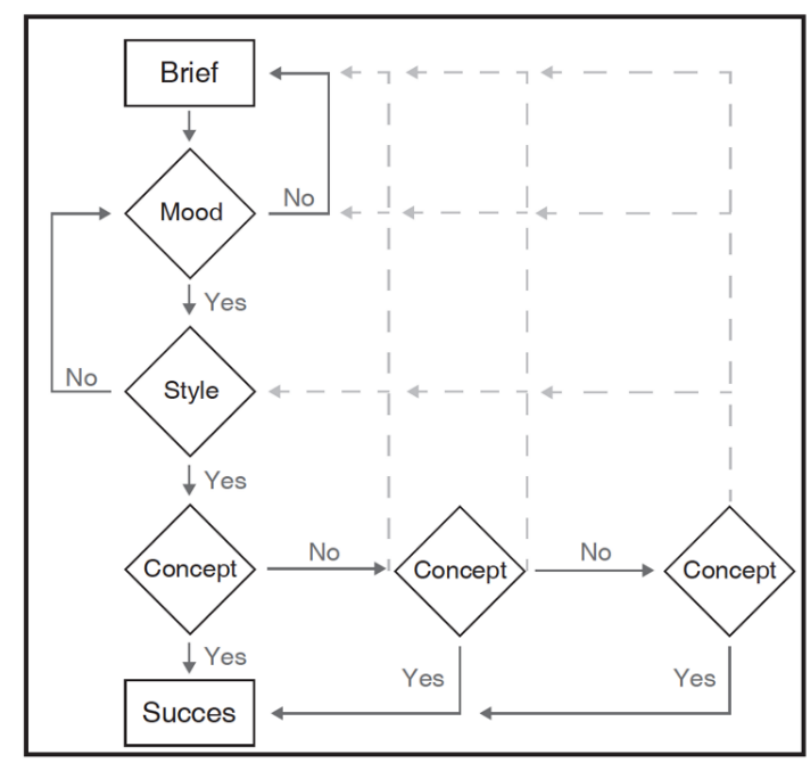

Figure 2. Flow of the process

\section{METHODOLOGY}

During the research period several different projects has been used to collect information and covers at least 8 different companies that are already established in the market. The companies are looking for new designs and have presented a brief to the design consultancies before each project. Ongoing feedback sessions took place between intern and senior designer and between the consultancy and the client. In all the projects, visual boards have been used to communicate concepts and ideas which has laid the ground for the empirical research.

Data collection was done qualitatively, so that a situated reflective view of the specific scenarios was possible. Participatory ethnographic field work made it possible to collect data through three different means; first the actual visual boards were collected and analysed, second field notes from the junior designers that created the boards, both during the development of the boards and after presenting them, third semi structured interviews with senior designers from two design consultancies, who reviewed the boards. To understand how and what directs the designers progress and attention. The semi-structured interview guides were structured based on the theory derived, served as the main structure for data collection during the ethnographic fieldwork.

The data was categorised, and new unanticipated patterns were revealed. The systematic combining method was used to constantly iterate on all elements of the paper [7]. This means that each time new insights and unanticipated findings emerged, the theoretical framework was modified to better suit the findings. Thus, some patterns were defined by theory, others emerged from the data. To gain an overview of all the boards according to the theory, a table of all 33 boards were done. Every time a board was registered it was categorised. In the analysis, a grouping was done to identify similarities and differences based on selected cases/boards in each group. This helped gain an overview of the comments attained through the semi structured interviews and laid ground for a deeper investigation of the specific scenarios.

\section{ANALYSIS}

The case studies take its offset in two design consultancies. Both companies deal with clients every day and try to fulfil their needs while pushing them to challenge the design. The case studies will reflect the work done by two design students and the feedback gotten from the senior designers / instructors at the 


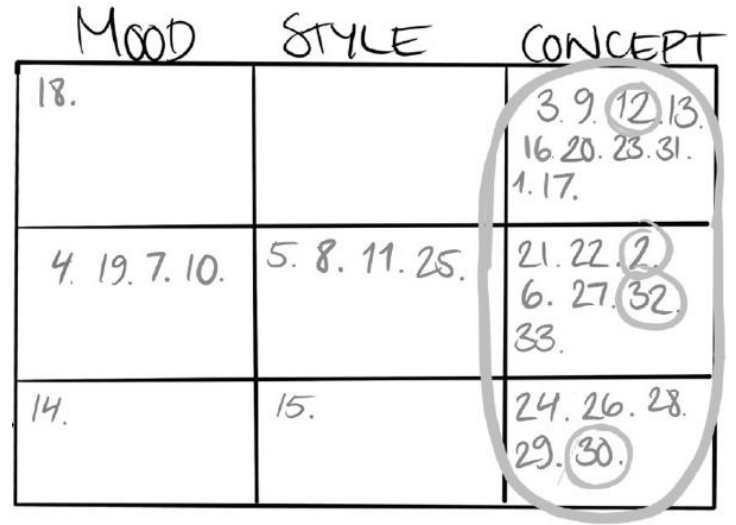

Figure 3. Categorization

\subsection{Mood board}

The feedback received on this mood board was converging as the senior designer wanted the pictures to be rearranged in a more geometric "grid". Although he found the pictures chosen appropriate and the message clearly communicated, the layout of the board disturbed the message. The junior designer did were surprised to get feedback to the layout of the board. It is important to consider how the layout can influence the overall perception of the mood board in a negative manner. Small changes like the placement of the pictures or captions can make an important difference when it comes to moving forward in the process.

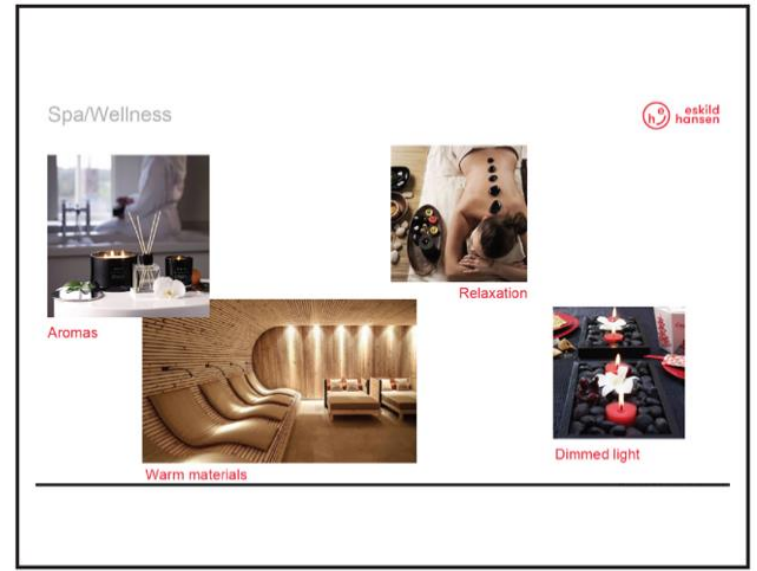

Figure 4. Mood board

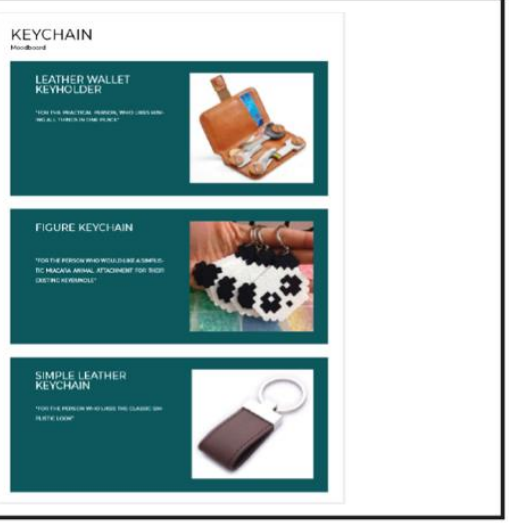

Figure 5. Mood board

The senior designer did not understand the "mood" of these pictures. He wanted a more "specific" mood board and clearer message. He did not think the specific "feeling" was communicated clearly enough for it to be used, and he therefore wanted some new pictures that "zoomed in" on different elements, which provoke a specific mood/feeling in a restaurant. Whereas the junior designer expected to get feedback on the board and its layout, the feedback instead turned out to be focussing on the message of it.
The intention of the board was misunderstood because it did not fit in with the style that the client was looking for. The senior designers were concerned that the client would see the homemade panda keychain and get scared away before we got to tell them the meaning behind it. The misunderstanding caused a total revamp of the entire mood board, since they also changed their mind with how the images should be presented. At first the senior designers wanted 3 different pictures with a small explanatory text and afterwards they wanted to focus on less directions and with no text at all, since the image should be self-explaining.

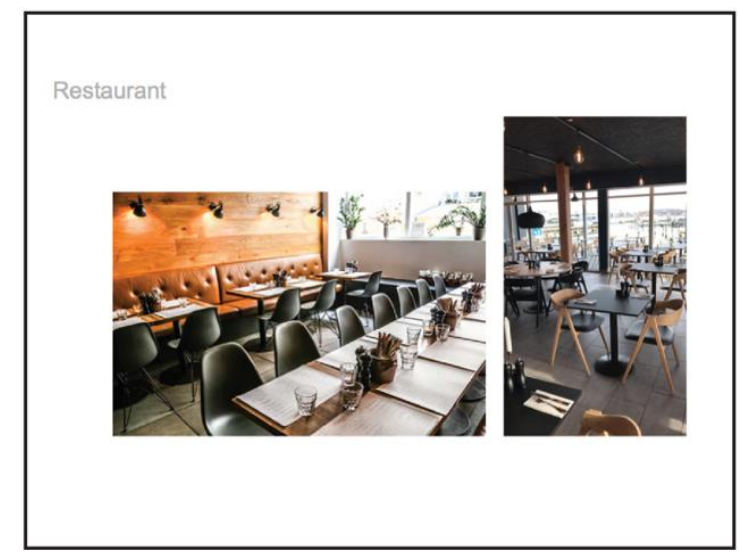

Figure 6. Mood board 


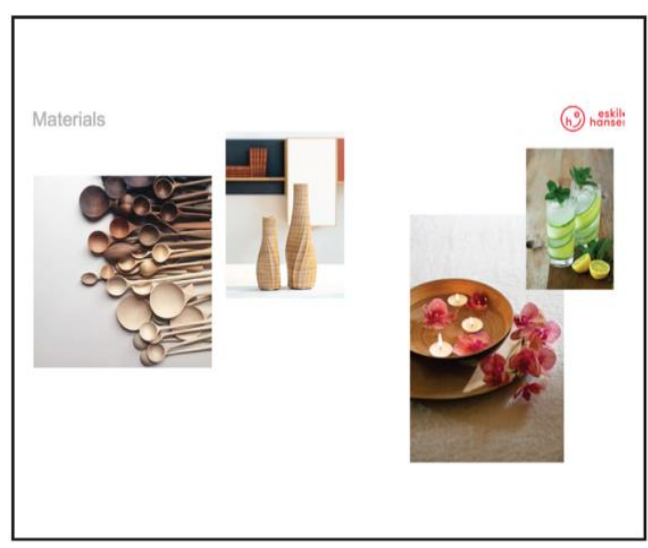

Figure 7. Style board

\subsection{Style board}

The feedback received on this style board unexpectedly focused on a misunderstanding. The senior designer thought the picture with the kitchen spoons gave a wrong "impression", as they took focus from the actual message which was showing different types of wood. This confused the overall message, as kitchen spoons does not fit with the spa context shown in the mood board. He wanted the message of the picture specified further. This is an example of how difference in comprehensions can affect the message of the board in different directions. This show the importance of creating a common understanding when creating style boards

\subsection{Concept board}

It was expected to get feedback on the concepts expression and shape to know whether we were aiming in the right direction. However, the feedback revolved around the production costs, as this were an important factor that would limit the freedom of design. The wooden elements were quite big, and the concerns involved it being too expensive to produce since it is one solid piece of turned wood. This was quite frustrating for the junior designer since it was expected to get some overall feedback, but the focus lingered on the details. Within this stage it is relevant to keep the production options in mind, because if things get too expensive for the client, they might not proceed with the concept.
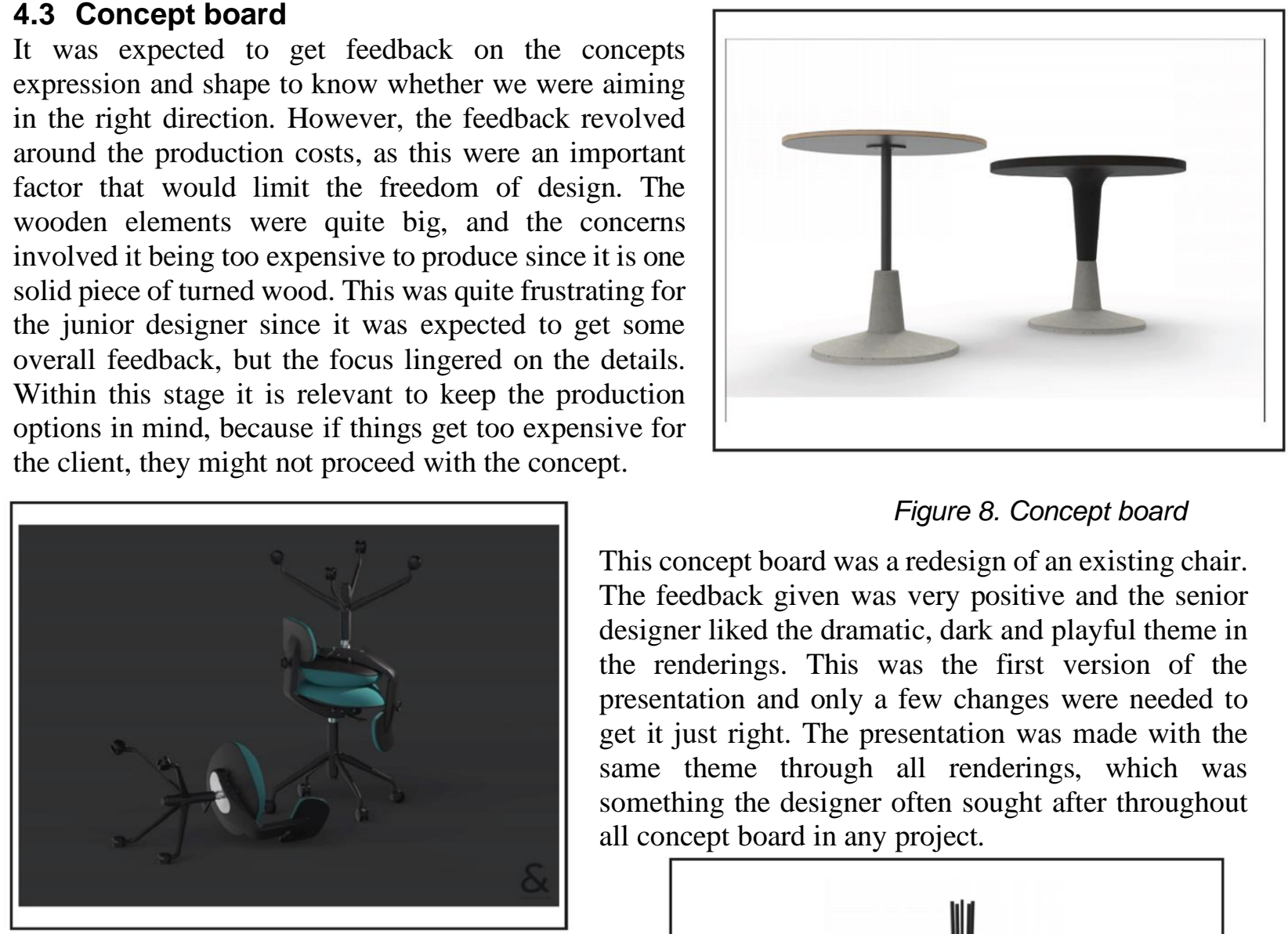

Figure 8. Concept board

This concept board was a redesign of an existing chair. The feedback given was very positive and the senior designer liked the dramatic, dark and playful theme in the renderings. This was the first version of the presentation and only a few changes were needed to get it just right. The presentation was made with the same theme through all renderings, which was something the designer often sought after throughout all concept board in any project.

Figure 9. Concept board

The feedback given encouraged making small corrections, which converged the process as it would be ready to show to the client, when the changes was made. The senior designer liked the overall principles of the concept, but felt that it needed some minor changes before it could be taken further, such as spreading the pins wider, adding a wooden cap on the pins, make the middle ring smaller and on the inside of the pin instead of the outside. The feedback was mainly focused on the product details and materials.

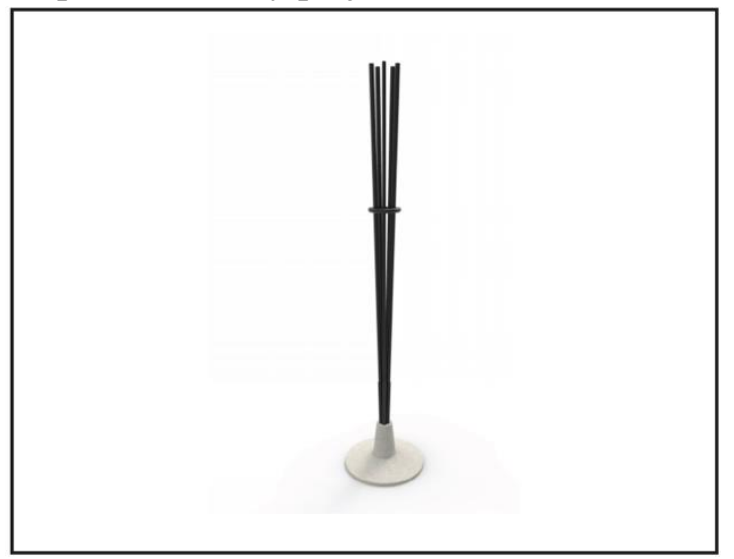

Figure 10. Concept board 
This concept board was presented for the senior designer to get the final feedback before presenting it for the client. The designer had no comments on the overall concept or the layout but was very focused on the mounting of the oil cap into the bottom part. The designer felt it would be a too expensive solution for a low-tech product like this and wanted to redesign the cap into one without the thread.

The feedback given on this concept board also focused on the clients' production skills. The concept got the response that it would be too hard for the client to produce the textured glass. The senior designer guided towards other textures that would fit better in with their processes. This resulted in diverging to explore new ways to implement the other production method. When creating a concept board in the later phases it is important to pay attention to what kind of small details the clients already use to separate them from others on the market.

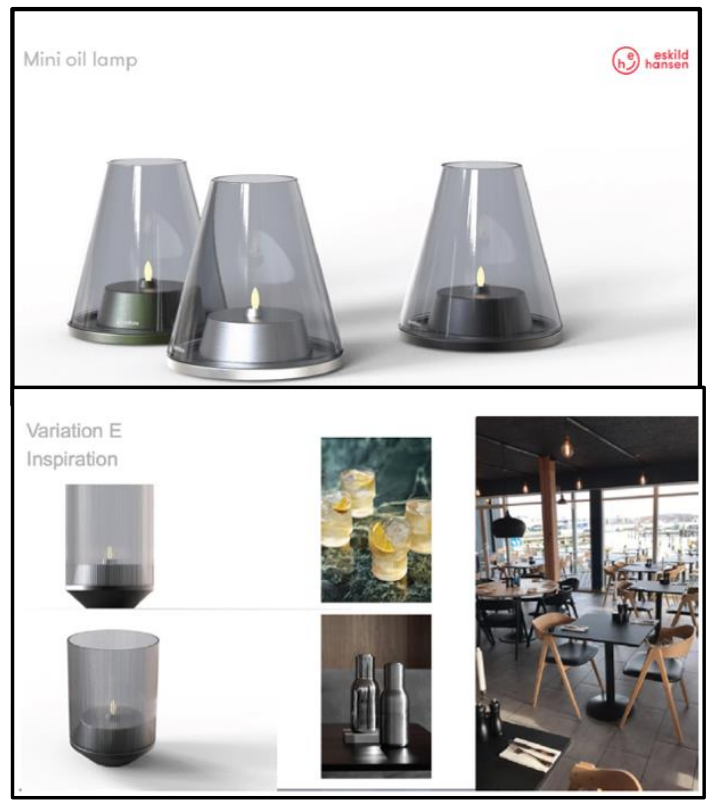

Figure $11+12$. Concept board

\section{Discussion}

By analysing the 33 boards made by design students and the feedback these got from senior designers, it has helped our understanding of visual boards, we have identified several insights.

First, when working with mood boards and style boards it sometimes occurs that it creates a conflict between the intended communicated message and what the viewer perceives. As a design process is filled with linguistic restrictions and communication barriers, that can feel fuzzy for a novice, it is important to be specific with the junior designer in how to set the mood and create a story that appeals to the viewers, e.g. keep the pictures within the spa setting, or zoom in on the aspects, you don't want me to miss. That is the senior designer, have more experience in, what leads to misunderstandings.

Second, a common denominator, when looking at the similarities of the feedback on concept boards, is a focus on details. In the early stage of the concept board the attention to detail can feel frustrating if the student/junior designer expected feedback on the overall concept and therefore did not consider the details as a discarding factor. The examples show that concept board regardless of stage receive feedback on both overall concept and details. For example, when developing the concept board, the client's production, process and materials should be considered already from the early stage.

Third, the students through the guidance of senior designers learned, that the purpose of the concept board is to culminate all the boards and often consists of different ways to show all the facets and details of the concept. Visualizing the concept in a context is often a big part of the concept board. This enables the viewer to experience how the concept would fit in with the initial brief and mood board. Moreover, that the mood board considers, enhances or somehow emphasizes the clients brand identity or image.

\section{REFERENCES}

[1] Schön, D. The reflective practitioner. 1938, New York, 1083.

[2] Cassidy, T. The Mood Board Process Modelled and Understood as a Qualitative Design Research Tool. 2011. Fashion Practice, Volume 3, Issue 2, 225-252

[3] Garner, S., \& McDonagh-Philp, D. Problem interpretation and resolution via visual stimuli: the use of 'mood boards' in design education. 2001. Journal of Art\& Design Education, 20(1),57-64.

[4] Lucero, A. Framing, aligning, paradoxing, abstracting, and directing how design mood boards work. 2012. In Proceedings of the designing interactive systems conference (pp. 438-447).

[5] Endrissat, N., Islam, G., \& Noppeney, C. Visual organizing: Balancing coordination and creative freedom via mood boards. 2016. Journal of Business Research, 69(7), 2353-2362.

[6] Mcdonagh, D. \& Storer I. Mood Boards as a Design Catalyst and Resource: Researching an Under-Researched Area. (2004.The Design Journal, 7:3. 16-31

[7] Dubois, A. \& Gadde L. Systematic combining: an abductive approach to case research.2002. Journal of Business Research 55, $553-560$. 